\title{
Transcription Factor Stat3 Stimulates Metastatic Behavior of Human Prostate Cancer Cells in Vivo, whereas Stat5b Has a Preferential Role in the Promotion of Prostate Cancer Cell Viability and Tumor Growth
}

Lei Gu, ${ }^{*}$ Ayush Dagvadorj, ${ }^{*}$ Jacqueline Lutz, ${ }^{*}$ Benjamin Leiby, ${ }^{\dagger}$ Gloria Bonuccelli, ${ }^{*}$ Michael P. Lisanti, ${ }^{*}$ Sankar Addya, ${ }^{\ddagger}$ Paolo Fortina, ${ }^{\ddagger}$ Abhijit Dasgupta, ${ }^{\dagger}$ Terry Hyslop, ${ }^{\dagger}$ Lukas Bubendorf, ${ }^{\S}$ and Marja T. Nevalainen ${ }^{*}$ đTII

\begin{abstract}
From the Departments of Cancer Biology, "Medical Oncology, and Urology," and the Nucleic Acid Facility, ${ }^{\ddagger}$ Kimmel Cancer Center, and the Department of Pharmacy and Experimental Therapeutics, ${ }^{\dagger}$ Thomas Jefferson University, Philadelphia, Pennsylvania; and the Institute for Pathology, University of Basel, Basel, Switzerland
\end{abstract}

Identification of the molecular changes that promote viability and metastatic behavior of prostate cancer is critical for the development of improved therapeutic interventions. Stat $5 a / b$ and Stat 3 are both constitutively active in locally-confined and advanced prostate cancer, and both transcription factors have been reported to be critical for the viability of prostate cancer cells. We recently showed that Stat 3 promotes metastatic behavior of human prostate cancer cells not only in vitro but also in an in vivo experimental metastases model. In this work, we compare side-byside $S t a t 5 a / b$ versus Stat 3 in the promotion of prostate cancer cell viability, tumor growth, and induction of metastatic colonization in vivo. Inhibition of Stat $5 \mathrm{a} / \mathrm{b}$ induced massive death of prostate cancer cells in culture and reduced both subcutaneous and orthotopic prostate tumor growth, whereas Stat3 had a predominant role over $S t a t 5 a / b$ in promoting metastases formation of prostate cancer cells in vivo in nude mice. The molecular mechanisms underlying the differential biological effects induced by these two transcription factors involve largely different sets of genes regulated by $S t a t 5 a / b$ versus $S t a t 3$ in human prostate cancer model systems. Of the two Stat 5 homologs, Stat $5 \mathrm{~b}$ was more important for supporting growth of prostate cancer cells than Stat5a. This work provides the first mechanistic comparison of the biological effects induced by transcription factors $S t a t 5 a / b$ versus Stat 3 in prostate cancer. (Am J Pathol 2010, 176:1959-1972; DOI: 10.2353/ajpath.2010.090653)

Presently, there are no effective pharmacological therapies for metastatic and castration-resistant prostate cancer. ${ }^{1}$ Prostate cancer develops resistance to androgendeprivation therapy within two to three years on average. ${ }^{1}$ Disseminated prostate cancer, in turn, is the lethal form of the disease. The molecular mechanisms underlying progression of prostate cancer to castration-resistant and metastatic disease are largely unclear, which has inhibited rational-based drug design for advanced prostate cancer.

Transcription factors Stat5 and Stat3 are both constitutively active in clinical prostate cancers ${ }^{2-8}$ and have been reported to promote growth of prostate cancer

Supported by American Cancer Society (RSG-04-196-01-MGO), Department of Defense Prostate Cancer grants (W81XWH-05-01-0062 and W81XWH-06-1-0076), and National Institutes of Health $\mathrm{NCl}$ (1RO1CA113580-01A1) to M.T.N. Shared Resources of Kimmel Cancer Center are partially supported by National Institutes of Health grant CA56036-08 (Cancer Center Support grant, to Kimmel Cancer Center).

L.G. and A.D. contributed equally to this study.

Accepted for publication December 14, 2009.

Supplemental material for this article can be found at $h t t p: / / a j p$. amjpathol.org

A guest editor acted as Editor-in-Chief for this manuscript. No person at Thomas Jefferson University or Albert Einstein College of Medicine was involved in the peer review process or final disposition for this article.

Address reprint requests to Marja T. Nevalainen, M.D., Ph.D., Department of Cancer Biology, Medical Oncology, Urology, Kimmel Cancer Center, Thomas Jefferson University, 233 S. 10 ${ }^{\text {th }}$ Street, BLSB 309, Philadelphia, PA 19107. E-mail: marja.nevalainen@jefferson.edu or marja.nevalainen@ kimmelcancercenter.org. 
cells. ${ }^{2,5,9-12}$ Stat5 and Stat3 are members of the sevenmember Stat gene family of transcription factors. ${ }^{13}$ There are two highly homologous isoforms of Stat5, 94-kDa Stat5a and 92-kDa Stat5b with 93\% sequence homology, but are encoded by separate genes. ${ }^{13}$ Stat5a/b and Stat 3 share approximately $31 \%$ sequence homology and possess a similar structural organization comprising the following domains: N-terminal, coiled-coil, DNA-binding, $\mathrm{SH} 2$, and transactivation domain, which are all important for proper functioning. ${ }^{14}$ The transactivation domain varies considerably in both length and sequence between different Stat family members. The transactivation domain binds critical co-activators and is therefore directly involved in facilitating the initiation of transcription. ${ }^{14,15}$ Phosphorylation of a C-terminal tyrosine residue activates Stat3 (Y705) and Stat5 (5a, Y694; 5b Y699). ${ }^{14}$ Activation of Stat3 is supplemented by phosphorylation of a specific serine residue of Stat3 (S727), ${ }^{15}$ whereas the corresponding serine phosphorylation of Stat5 ( $5 \mathrm{a}, \mathrm{S} 725 ; 5 \mathrm{~b}$, S730) might have a negative role in transcriptional activity of Stat5. ${ }^{16-18}$ Once active, Stats dimerize through a phosphotyrosine-SH2 domain interaction ${ }^{19,20}$ and translocate to the nucleus to regulate transcription by direct binding to the target gene promoters. ${ }^{14}$ Both Stat5 and Stat3 recognize the same palindromic consensus sequence of TTCN $_{2-4} \mathrm{GAA}$, which is referred to as a GAS element ( $\gamma$-interferon activation sequence). ${ }^{21}$

Stat $5 a / b$ is critical for the viability of human prostate cancer cells in culture, for human prostate xenograft tumor growth in vivo ${ }^{2,9,10}$ and for prostate cancer progression in TRAMP mouse model. ${ }^{22}$ In clinical prostate cancers, active Stat5a/b protein expression is abundant in prostate cancer cells, but not in normal prostate epithelium. ${ }^{2}$ Moreover, expression of active Stat5a/b in prostate cancer is associated with high histological grade of the cancer. ${ }^{3,4}$ We showed recently a co-action between Stat5a/b and androgen receptor (AR) in prostate cancer cells, where Stat5a/b promoted transcriptional activity of $A R$, and $A R$, in turn, increased transcriptional activity of Stat5a/b. ${ }^{23}$ The transcriptional synergy between Stat5a/b and AR supports the results of our earlier study which showed that active $\mathrm{Stat} 5 \mathrm{a} / \mathrm{b}$ expression in primary clinical prostate cancer predicted early prostate cancer recurrence. ${ }^{3}$ Autocrine prolactin in prostate cancer has been demonstrated to activate $S t a t 5 a / b^{4,9}$ via Jak2 tyrosine kinase. ${ }^{4}$ The relative importance of Stat5a versus Stat5b in promotion of prostate cancer cell growth has been unclear.

Besides Stat5a/b, transcription factor Stat3 is implicated in promotion of growth and progression of prostate cancer. Activation of Stat3 has been associated with advanced stage of prostate cancer, ${ }^{5-8,24}$ and Stat3 interacts with AR in prostate cancer cells. ${ }^{25-28}$ Importantly, several reports have demonstrated that Stat3 promotes proliferation and inhibits apoptosis in DU145 and LNCaP prostate cancer cell lines. ${ }^{5,11,29,30}$ Recently, we showed that Stat3 dramatically increases metastases formation of human prostate cancer cells in nude mice in an experimental metastases assay, and Stat3 induced migration of human prostate cancer cells in vitro. ${ }^{31}$
In this work, we compared side-by-side the effects of Stat5a versus Stat5b versus Stat3 in the promotion of prostate cancer cell viability in vitro and tumor growth in vivo. In addition, we compared Stat5a/b to Stat3 in promoting metastatic dissemination of prostate cancer cells in vivo. The data indicate that the effects of Stat5a/binhibition on reduction of prostate cancer cell viability in culture and subcutaneous and orthotopic prostate tumor growth in nude mice were greater than those of Stat3. Stat3, in turn, was more effective than Stat5a/b in inducing metastases formation of human prostate cancer cells in vivo. These findings were supported by the gene expression analysis, which indicated that Stat5a/b and Stat3, despite both recognizing the GAS consensus sequence, regulate to a large extent different sets of genes in human prostate cancer cells. When the two Stat5 homologs were compared, Stat5b was more critical than Stat5a in supporting the viability of prostate cancer cells. Finally, Stat5a/b inhibition did not reduce the viability of normal human prostate epithelial cells or cancer cell lines originating from tissues other than prostate.

\section{Materials and Methods}

\section{Cell Culture}

DU145, PC-3, LNCaP, and CWR22Rv1 human prostate cancer cells (American Type Culture Collection, Manassas, VA) were grown in RPMI-1640 medium (Mediatech, Inc. Herndon, VA). The growth medium contained $10 \%$ fetal bovine serum (FBS; Quality Biological, Inc., Gaithersburg, MD), $2 \mathrm{mmol} / \mathrm{L}$ L-glutamine and penicillinstreptomycin (Mediatech, Inc.; $50 \mathrm{IU} / \mathrm{ml}$ and $50 \mu \mathrm{g} / \mathrm{ml}$, respectively). LNCaP cells were grown in the presence of $0.5 \mathrm{nmol} / \mathrm{L}$ dihydrotestosterone (DHT). Normal human prostate epithelial cells $\mathrm{RC} 165 \mathrm{~N}$ and $\mathrm{RC} 170 \mathrm{~N}^{32}$ were grown in keratinocyte-serum-free (keratinocyte-SFM; Gibco, Grand Island, NY) medium supplemented with L-glutamine, epidermal growth factor, and bovine pituitary extract (Gibco). Human breast cancer (T47D and MCF-7), pancreatic cancer (Hs766T and CAPAN), melanoma (A2058), liver cancer (HCT116), and lung cancer (A549) cell lines were grown in DMEM (Invitrogen, Carlsbad, CA) supplemented with 10\% FBS (Quality Biological, Inc.), 2 mmol/L L-glutamine, and penicillin-streptomycin (Mediatech, Inc.).

\section{Solubilization of Proteins, Immunoprecipitation, and Immunoblotting}

Cells were lysed in lysis buffer $(10 \mathrm{mmol} / \mathrm{L}$ Tris- $\mathrm{HCl}[\mathrm{pH}$ 7.5], $5 \mathrm{mmol} / \mathrm{L}$ EDTA, $50 \mathrm{mmol} / \mathrm{L} \mathrm{NaCl}, 30 \mathrm{mmol} / \mathrm{L}$ sodium pyrophosphate, $50 \mathrm{mmol} / \mathrm{L}$ sodium fluoride, $1 \mathrm{mmol} / \mathrm{L}$ sodium orthovanadate, $1 \%$ Triton $\mathrm{X}-100,1 \mathrm{mmol} / \mathrm{L}$ phenylmethylsulphonylfluoride, $5 \mu \mathrm{g} / \mathrm{ml}$ aprotinin, $1 \mu \mathrm{g} / \mathrm{ml}$ pepstatin A, and $2 \mu \mathrm{g} / \mathrm{ml}$ leupeptin), and the protein concentrations of the whole cell lysates were determined by the Bradford method (BioRad Laboratories Inc., Hercules, CA). The cell lysates were immunoprecipitated for 2 hours at $4^{\circ} \mathrm{C}$ with anti-Stat5a or anti-Stat5b pAbs (each 
$1.2 \mu \mathrm{g} / \mathrm{ml}$; Advantex Bioreagents, Conroe, TX) or antiStat3 pAb (1.2 $\mu \mathrm{g} / \mathrm{ml}$, Santa Cruz Biotechnology, Inc., Santa Cruz, CA). Antibodies were captured by incubation with protein A-Sepharose beads (Pharmacia Biotech, Piscataway, NJ) for 60 minutes. The filters were blotted with anti-phosphotyrosine-Stat5a/b (Y694/Y699) monoclonal antibody (mAb; $1 \mu \mathrm{g} / \mathrm{ml}$, Advantex Bioreagents), antiStat5a/b mAb (1:250) (Transduction Laboratories, Inc.), anti-Stat3 pAb (1:1000; Santa Cruz Biotechnology), antiphospho-tyrosine Stat3 pAb (Y705; 1:1000; Cell Signaling, Danvers, MA) or anti-actin pAb (1:4000; Invitrogen). The immunoreaction was detected by horseradish peroxidase-conjugated secondary antibodies in conjunction with enhanced chemiluminescence substrate mixture (Amersham, Piscataway, NJ), and exposed to film.

\section{Generation of Adenoviruses for Gene Delivery of Wild-Type and Dominant-Negative Forms of Stat5a/b and Stat3}

We cloned pcDNA-CMV-WTStat5b (AdWTStat5b) and pcDNA-CMV-DNStat5a/b (AdDNStat5a/b) into adenoviral vector using BD Adeno-X Expression System 2 (BD Biosciences Clontech, Palo Alto, CA) according to the manufacturer's protocol as described previously. ${ }^{22}$ Adenoviruses carrying a human wild-type Stat3 (AdWTStat3) and a dominant-negative Stat3 (AdDNStat3; C-terminally truncated at amino acid 715$)^{33}$ were kindly provided by Dr. Hallgeir Rui at Thomas Jefferson University. Viral stocks were expanded in large-scale cultures, purified by double cesium chloride gradient centrifugation, and titered side-by-side by a standard plaque assay method in QBI293A cells as per the manufacturer's instructions (Qbiogene, Carlsbad, CA).

\section{siRNA Transfection}

DU145 and CWR22Rv1 prostate cancer cells were transfected with the scramble siRNA or siRNAs targeted to human Stat3, Stat5a, or Stat5b (Dharmacon, Lafayette, CO; 100 pmol of siRNA) using transfection reagent Lipofectamine 2000 (Invitrogen).

\section{Cell Growth and Viability Assay}

The number of living cells was determined by counting the attached cells using a hemacytometer and trypan blue exclusion. In addition, the cell viability was determined by 3-(4,5 Dimethylthiazol-2-yl)-5-(3-carboxymethoxyphenyl)-2-(4-sulfophenyl)-2H-tetrazolium assay (Promega, Madison, WI). In brief, after plating, the cells were infected next day with AdWTStat5b, AdDNStat5a/b, AdWTStat3, AdDNStat3, or AdLacZ at multiplicity of infection (MOI) 5. After 72 hours, the proportion of viable cells in each treatment group in sextuplicates was determined by tetrazolium conversion to its formazon dye (Promega) at 490 nm (POLARstar OPTIMA, BMG Labtech).

\section{Subcutaneous Prostate Cancer Xenograft Tumors}

Castrated male athymic mice (Taconic; Germantown, NY) were cared for according to the institutional guidelines. Sustained-release DHT pellets (90-day release, 1 pellet/mouse; Innovative Research of America, Sarasota, FL) were implanted subcutaneously (s.c.) three days before the tumor cell inoculations to normalize the circulating DHT levels. Briefly, DU145 cells were infected 24 hours before the inoculation to the mice with AdWTStat3, AdDNStat3, AdWTStat5b, AdDNStat5a/b, or AdLacZ at MOI 5. DU145 cells $\left(20 \times 10^{6}\right)$ were mixed with one half of the total injection volume $(0.2 \mathrm{ml})$ with Matrigel (BD Bioscience, San Jose, CA), and injected s.c. to the flanks of the nude mice (1 site/mouse). When the tumors reached 15 to $20 \mathrm{~mm}$ in diameter, the mice were sacrificed, and the tumor tissues were harvested. The volumes of the tumors were measured twice a week and calculated using the formula $V=(\pi / 6) \times d_{1} \times\left(d_{2}\right)^{2}$, with $d_{1}$ and $d_{2}$ being two perpendicular tumor diameters.

\section{Orthotopic Inoculation of Human Prostate Cancer Cells}

Athymic male nude mice (6 to 8 weeks; Taconic, Germantown, NY) were anesthesized with $2 \%$ isoflurane, and an incision was made in the lower abdomen through skin and peritoneum to access the dorsolateral prostate. A suspension of DU145 cells $\left(1 \times 10^{6}\right)$ in $20 \mu$ l of PBS was injected into the dorsalateral prostate, and the wound was closed by single-stitch technique using a 4-0 suture. Before (24 hours) orthotopic inoculation, DU145 cells had been infected with AdLacZ, AdWTStat3, AdDNStat3, AdWTStat5b, or AdDNStat5a/b at MOI 5. Mice were sacrificed 8 weeks after the tumor cell inoculation, and the tumors were measured and photographed. The volumes of the tumors were calculated using the formula $V=(\pi / 6) \times d_{1} \times\left(d_{2}\right)^{2}$, with $d_{1}$ and $d_{2}$ being two perpendicular tumor diameters.

\section{Tail-Vein Injections of Human Prostate Cancer Cells}

Castrated male athymic mice (Taconic) were implanted with DHT pellets (90-day release, 1 pellet/mouse; Innovative Research of America) to normalize the circulating levels of DHT. DU145 cells were infected with AdLacZ, AdWTStat3, AdWTStat5a, or AdWTStat5b at MOI 5. After 24 hours, $1 \times 10^{6}$ cells were suspended in $0.2 \mathrm{ml}$ of PBS and injected into the lateral tail vein using 27-gauge needle. The mice were sacrificed 8 weeks after inoculation, and the lungs were perfused with $1.5 \mathrm{ml}$ of $15 \%$ India Ink dye in 3.7\% formalin. Lungs were then removed and bleached in Fekete's destaining solution $(70 \%$ ethanol, $3.7 \%$ formaldehyde, $0.75 \mathrm{~mol} / \mathrm{L}$ glacial acetic acid). Lung surfaces were photographed, and the numbers of metastases nodules were scored. 


\section{RNA Preparation and Gene Expression Profiling}

Forty-eight hours after the siRNA transfection, total RNA was prepared using the Qiagen RNeasy Mini kit (Qiagen, Valencia, CA). A DNase I digestion step was included to eliminate DNA contamination. Each group (controlsiRNA, Stat5a/b-siRNA and Stat3-siRNA) was done in triplicate, and RNA samples from each group were not pooled. RNA was quantified on a Nanodrop ND-100 spectrophotometer, followed by RNA quality assessment by analysis on an Agilent 2100 Bioanalyser (Agilent Tehnologies, Palo Alto, CA). A total of $2 \mu \mathrm{g}$ of RNA from each sample was used for Affymetrix one-cycle target labeling method as recommended by the manufacturer (Affymetrix, Santa Clara, CA). Each Affymetrix Genechip for Human Genome 133 Plus 2.0 was hybridized for 16 hours with biotin-labeled fragmentated cRNA $(10 \mu \mathrm{g})$ in $200 \mu \mathrm{l}$ of hybridization cocktail according to Affymetrix protocol. Arrays were washed and stained using Genechip Fluidic Station 450, and hybridization signals were amplified using antibody amplification with goat IgG (Sigma-Aldrich) and anti-streptavidin biotinylated antibody. Chips were scanned on an Affymetrix GeneChip Scanner 3000 using GeneChip Operating Software version 3.0.

\section{Statistical Analysis}

For the analysis of the cell numbers after Stat5a/Stat5b/ Stat5ab/Stat3/control siRNA transfections, analysis of variance was used to compare groups with respect to the number of living cells. The residual variance was allowed to vary by group. $P$ values were adjusted using Bonferroni method to maintain an overall type I error rate of $5 \%$ for this experiment.

The two-sample $t$ test was used to compare the number of living cells in the group where Stat5ab was downregulated by $A d D N S t a t 5 a / b$ versus AdLacZ-infected cells, and the group where Stat3 was down-regulated by AdDNStat3 versus AdLacZ-infected cells. $P$ values were adjusted using Bonferroni method to maintain an overall type I error rate of $5 \%$ for this experiment.

For the analysis of subcutaneous DU145 xenograft tumors, the trajectory of log-transformed tumor volumes over time was modeled in two stages. At the first stage, robust regression was used to estimate the rate of growth (slope) of the log tumor volumes for each tumor. At the second stage, groups were compared with respect to average slopes using linear regression where each mouse's data were weighted by the inverse of the SE of the slope estimate in the first stage. Undetectable volumes were set to four before transformation for purposes of this analysis. The Wilcoxon rank sum test was used to compare groups at day 69.

The distribution of orthotopic tumor volumes by the treatment groups (AdDNStat3, AdWTStat3, AdWTStat5b, AdDNStat5a/b, and AdLacZ) was summarized using the median, interquartile range, and range. Pair-wise group comparisons were performed using the Wilcoxon rank sum test. Tumor volumes from AdDNStat5a/b were compared with AdWTStat5b and AdLacZ, and volumes from
AdDNStat3 were compared with AdWTStat3 and AdLacZ. $P$ values for these tests were adjusted using Bonferroni method to maintain an overall type I error rate of $5 \%$ for this experiment.

To determine the effects of Stat5a/b inhibition versus Stat3 inhibition on the growth of different cell types, DNStat5a/b expression was compared with WTStat5b, and DNStat3 expression was compared with WTStat3 within each cell type with respect to mean absorption levels using a two-sample $t$ test. $P$ values for the test were adjusted using the method of Benjamini and Hochberg to control the false discovery rate. $P<0.05$ was considered significant.

For the statistical analysis of the in vivo metastases assay, Wilcoxon rank sum test with exact $P$ values was used to compare the groups with respect to the number of lung nodules per mouse.

\section{Microarray Data Analysis}

The gene expression profiles of Stat5a/b versus Stat3 were analyzed in parallel in two different human prostate cancer cells lines, DU145 and CWR22Rv1. The chips ( $n=3$ Ctrl siRNA, $n=3$ Stat3 siRNA, $n=3$ Stat5a/b) were preprocessed using Robust Multiarray Average. ${ }^{34}$ The Affymetrix GeneChip for Human Genome 133 Plus 2.0 has 54,675 transcripts, and nonspecific filtering ${ }^{35}$ was done before analysis resulting in a single transcript for each of 15,992 annotated genes. Specifically, probe sets that did not have an associated Entrez Gene ID and Gene Ontology ID were filtered out. The probe set that exhibited maximal variability was chosen to represent each gene (defined by a unique Entrez Gene ID). Differential expression of each gene between Ctrl siRNA and Stat3 or Stat5a/b siRNA groups was assessed using a linear model with an empirical Bayes correction for the variance, as implemented in the Bioconductor $^{36}$ package limma. ${ }^{37}$ This allows a robust analysis of differential expression between Ctrl siRNA and Stat3 or Stat5a/b siRNA groups even in case of small sample size. The $P$ values were then corrected for multiple testing using the false discovery rate. ${ }^{38}$ This analysis establishes whether the fold-change (FC) observed is large enough compared with the variability in the gene expression across the samples to meet our statistical significance criterion. We considered the genes with a false discovery rate-adjusted $P$ value of $<=0.01$ to be statistically significant (see Supplemental Tables S1 and S2 at http://ajp.amjpathol.org).

\section{Results}

Stat5a/b Has a Preferential Role over Stat3 in Promoting the Viability of Human Prostate Cancer Cells in Vitro and Prostate Xenograft Tumor Growth in Vivo

To determine the biological effects of Stat5a/b versus Stat3 on human prostate cancer cell growth in culture, we 
first established the phosphorylation and total protein levels of Stat5a, Stat5b, and Stat3 in CWR22Rv1, LNCaP, and DU145 human prostate cancer cell lines. Immunoprecipitation and immunoblotting of Stat5a/b show persistent activation and expression of Stat5a and Stat5b in all three cell lines (Figure 1A). Immunoprecipitation of Stat3 indicated persistent Stat3 activation in only DU145 cells, whereas Stat3 protein was expressed in DU145, LNCaP, and CWR22Rv1 cells (Figure 1A).

Because persistent activation of both Stat5 and Stat3 was detected in DU145 cells, we decided to use this cell line as our first model system to compare the biological effects caused by inhibition of Stat5a/b versus Stat3. We designed siRNAs to inhibit selectively Stat5a/b or Stat3 in DU145 prostate cancer cells. First, we verified by Western blotting that siRNAs targeted to Stat5a/b did not affect Stat3 protein expression or Stat3 phosphorylation (Figure 1B). Stat3 siRNAs, in turn, did not affect the expression level of Stat5a/b as demonstrated in Figure 1B. DU145 cells were transfected with siRNAs against Stat5a/b or Stat3 for 48 hours, with scrambled siRNA as control, and Stat5a/b was immunoprecipitated and blotted with anti-Stat5a/b $\mathrm{mAb}$. Whole cell lysates of the same samples were immunoblotted for phosphorylated Stat3, total Stat3, and actin (Figure 1B). In the next set of experiments, DU145 cells were transfected with siRNAs against Stat5a/b or Stat3 for 72 hours, after which the cells were photographed (Figure 1, C and D), and the number of attached cells was determined. Inhibition of Stat5ab by RNA interference resulted in a 70\% decrease in attached and viable DU145 cells $(P<0.0001)$, whereas Stat3 inhibition decreased the number of viable cells by $20 \%$ compared with cells transfected with control siRNA $(P=0.15$; Figure 1C). Microscope photographs indicate dead and floating cells in the wells transfected with Stat5a/b siRNA (Figure 1D). Our previous work has demonstrated that prostate cancer cell death induced by Stat5 inhibition is apoptotic involving extensive DNA fragmentation and Caspase-3 and -9 activation. 2,9,10 In summary, these results demonstrate that $S t a t 5 a / b$ has a more important role than Stat3 in sustaining the viability of DU145 human prostate cancer cells in culture.

To determine the relative importance of the two Stat5 homologs for promotion of the viability of human prostate cancer cells, siRNAs specific to Stat5a or Stat5b were introduced to DU145 cells. The specificity of the siRNAs was verified by immunoprecipitation and Western blotting (Figure 1B). Inhibition of Stat5b by RNA interference resulted in almost similar decrease in the number of attached and viable DU145 cells compared with the group that was transfected with siRNAs targeting simultaneously both Stat5a and Stat5b $(P<0.0001$; Figure 1, C and D). In contrast, inhibition of Stat5a by Stat5a siRNAs did not affect significantly the cell viability compared with the controls $(P=1.0$; Figure $1, C$ and $D)$.

As the second methodological approach, Stat5a/b or Stat3 were inhibited by adenoviral (Ad) gene delivery of dominant-negative (DN) mutants of $S t a t 5 a / b^{10}$ and Stat $3,{ }^{33}$ respectively, with AdLacZ, AdWTStat5b, ${ }^{10}$ AdWTStat $3,{ }^{33}$ and mock-infected cells as controls. The transactivation domain was deleted from Stat5a and
Stat3 to create mutants of Stat $5 a / b$ and Stat3 that would inhibit transcriptional activity of Stat5a/b and Stat3, respectively. 2,10,33 All of the adenoviral constructs were propagated and titered side-by-side and tested by Western blotting for transfer of equal gene expression levels for each construct in human prostate cancer cells. DU145 cells were infected with AdWTStat5b, AdDNStat5a/b, AdWTStat3, or AdDNStat3, with AdLacZ (all at MOI 5) or mock-infected cells as controls, and the cells were photographed and the number of attached cells was determined after 72 hours (Figure 1, E and F). Inhibition of Stat5a/b by adenoviral expression of DNStat5a/b decreased the number of viable and attached DU145 cells by $87 \%$ compared with AdLacZinfected cells $(P<0.0001)$, whereas inhibition of Stat3 reduced the cell number by $30 \%(P=0.0014$; Figure $1 \mathrm{E})$. Microscope photographs verify extensive cell death in AdDNStat5a/b-infected wells as evidenced by cell rounding, detachment, and shrinkage (Figure 1F). Collectively, these results suggest Stat5b is the key regulator of DU145 prostate cancer cell viability in culture rather than Stat5a or Stat3.

Given the preferential role of Stat $5 \mathrm{a} / \mathrm{b}$ in promotion of prostate cancer cell viability in cell culture, we hypothesized that Stat5a/b also has a predominant role in the regulation of prostate xenograft tumor growth in nude mice. To test this hypothesis, we inhibited Stat5a/b by AdDNStat5a/b and Stat3 by AdDNStat3 in DU145 prostate cancer cells. Adenoviral gene delivery was performed 24 hours before inoculation of the cancer cells subcutaneously into flanks of nude mice. The mice had been castrated, and sustained-release DHT pellets were implanted to normalize the circulating androgen levels. Once tumors started to form on day 9 , the tumor sizes were measured once a week until day 69 of the experiment. The tumor volumes $(P=0.024)$ and the growth rate $(P=0.016)$ of prostate tumors both were significantly suppressed in Stat5a/b-inhibited group compared with the control group (AdWTStat5b), whereas the effects of Stat3 inhibition on the tumor volumes $(P=0.52)$ or the growth rate $(P=0.90)$ of subcutaneously grown prostate xenograft tumors were less consistent (Figure 2A).

In the second set of experiments, we compared the effects of Stat5a/b inhibition versus Stat3 on orthotopic prostate tumor growth in nude mice (Figure 2B). DU145 cells were infected with AdDNStat5a/b, AdWTStat5b, AdDNStat3, AdWTStat3, or AdLacZ 24 hours before inoculation to the dorsolateral prostates of athymic nude mice. After 8 weeks, the mice were sacrificed, the urogenital blocks were photographed, and the prostate tumor sizes were measured. When Stat5a/b was inhibited, the tumors were significantly smaller when compared with the tumors formed from AdWTStat5b-infected cells $(P=0.0032)$. Inhibition of Stat3 by AdDNStat3 moderately decreased the tumor sizes compared with the AdWTStat3-group ( $P=0.112$ ) or LacZ-group $(P=1.0$; Figure 2B), but did not reach statistical significance. In conclusion, these results suggest a preferential role for Stat5a/b rather than Stat3 in promotion of subcutaneous and orthotopic xenograft human prostate tumors in nude mice. 


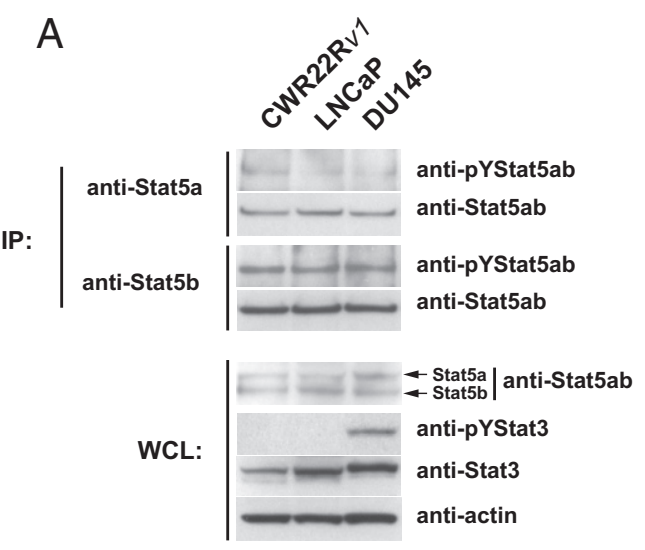

C

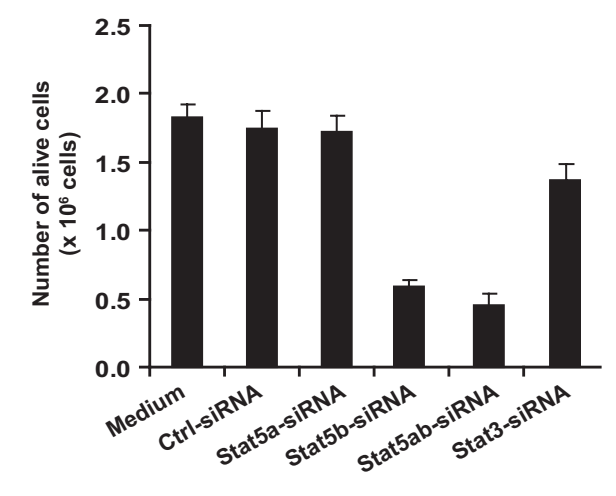

E

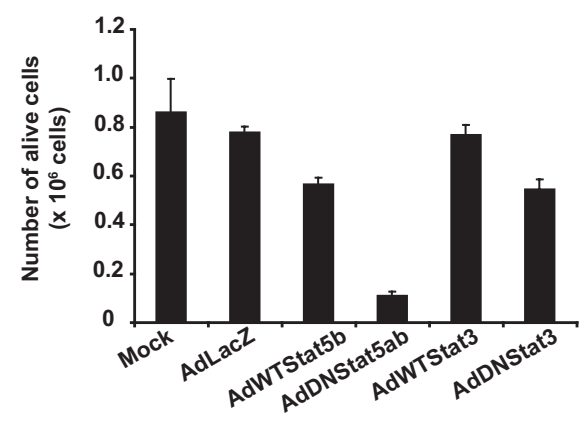

B

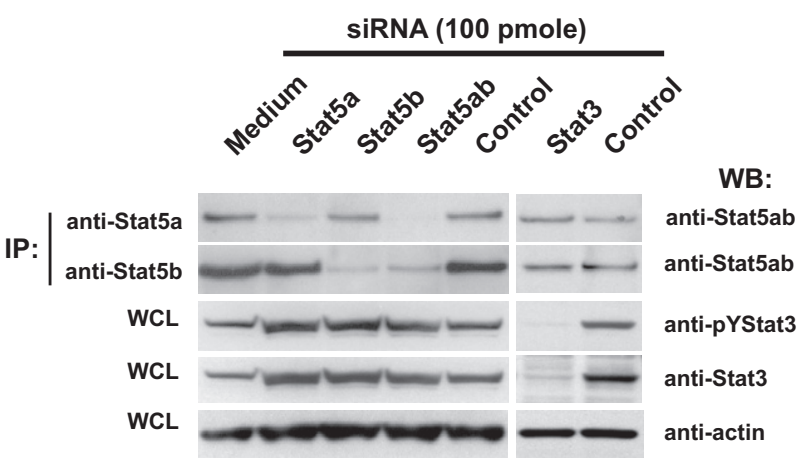

D

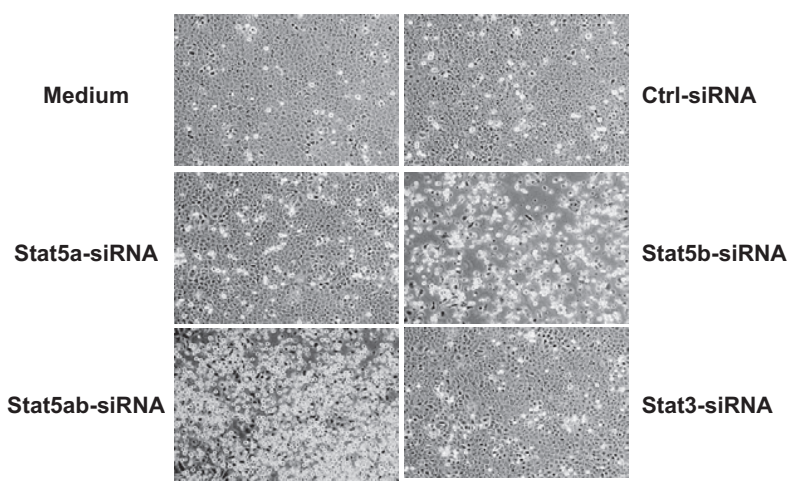

F

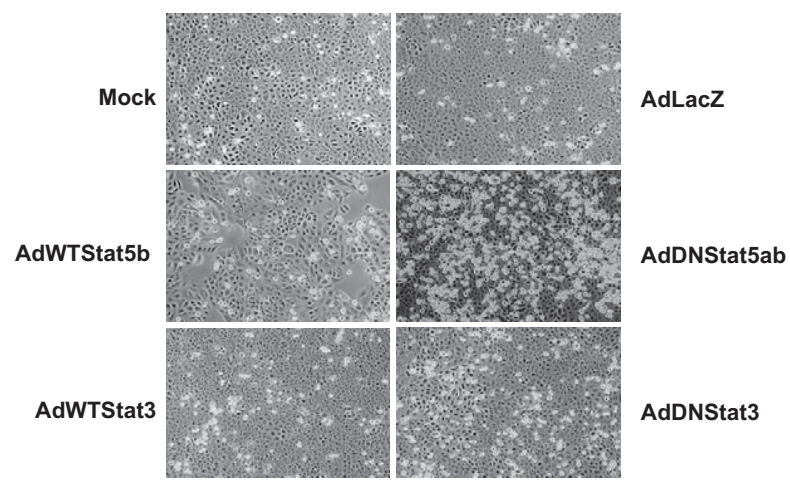

Figure 1. Inhibition of Stat $5 \mathrm{a} / \mathrm{b}$ caused a robust decrease in the number of viable DU145 human prostate cancer cells, whereas the effects of Stat 3 inhibition were less pronounced. A: Transcription factors Stat 5 and Stat 3 are both constitutively active in DU145 prostate cancer cells. Stat 5 a or Stat 5 b were immunoprecipitated (IP) from exponentially growing CWR22Rv1, LNCaP, and DU145 cells using anti-Stat5a or anti-Stat5b pAbs, and blotted (WB) with anti-phospho-Stat5a/b (anti-pYStat5a/b) antibody, as indicated. Whole cell lysates (WCL) were blotted with anti-phospho-Stat3 (anti-pYStat3) antibody. Filters were stripped and re-blotted with anti-Stat5ab or anti-Stat 3 mAbs, and whole cell lysates before IP were immunoblotted with anti-actin pAb. B: To verify the specificity of the siRNAs, DU145 cells were transfected with siRNA targeted to Stat5a, Stat5b, or Stat3, with scrambled siRNAs or nontransfected cells as controls. The cells were harvested 48 hours after the siRNA transfection. Stat $5 \mathrm{a}$ and Stat $5 \mathrm{~b}$ were immunoprecipitated with anti-Stat $5 \mathrm{a}$ and anti-Stat $5 \mathrm{~b}$ pAbs, respectively, and blotted with anti-Stat $5 \mathrm{a} / \mathrm{b}$ $\mathrm{mAb}$, as indicated. Whole cell lysates (WCL) of the same samples were blotted with anti-phospho-Stat3 (anti-pYStat3), anti-Stat3, or anti-actin pAbs. C: Inhibition of Stat5b by RNA interference decreased the number of viable DU145 cells, whereas the effects of Stat5a or Stat 3 inhibition were less evident. The number of live cells after inhibition of Stat $5 \mathrm{a}$, Stat $5 \mathrm{~b}$, Stat $5 \mathrm{a} / \mathrm{b}$, or Stat 3 by specific siRNAs, control group was incubated with transfection reagent only. After trypan blue exclusion, the attached viable DU145 cells were counted 72 hours after the siRNA transfection. The bars indicate mean \pm SD of triplicate wells. D: Microscope photographs of the DU145 cells 72 hours after the transfection show the cell morphology. siRNAs targeted to Stat $5 \mathrm{~b}$ or Stat $5 \mathrm{a} / \mathrm{b}$ induced massive detachment and rounding of DU145 cells, whereas Stat5a or Stat3 siRNA caused hardly detectable effects on the cell numbers or the cell morphology. E: Inhibition of Stat5a/b by adenoviral (Ad) gene delivery of a dominant-negative (DN) Stat $5 \mathrm{a} / \mathrm{b}$ decreased significantly the number of viable prostate cancer cells, whereas Stat 3 inhibition effects were only minor. DU145 cells were infected with AdWTStat5b, AdDNStat5a/b, AdWTStat3, AdDNStat3, or with AdLacZ at MOI 5 using mock-infected cells as an additional control. After trypan blue staining, the cells were photographed and counted after 72 hours. The bars indicate mean \pm SD of triplicate wells. F: Microscope photographs demonstrate the cell morphology after 72 hours infection of the cells with AdDNStat5a/b, AdWTStat5b, AdDNStat3, AdWTStat3 versus AdLacZ or mock-infected cells. Inhibition of Stat $5 \mathrm{a} / \mathrm{b}$ induced detachment, rounding, and shrinkage of the cells, which are all characteristics of apoptosis. 
A

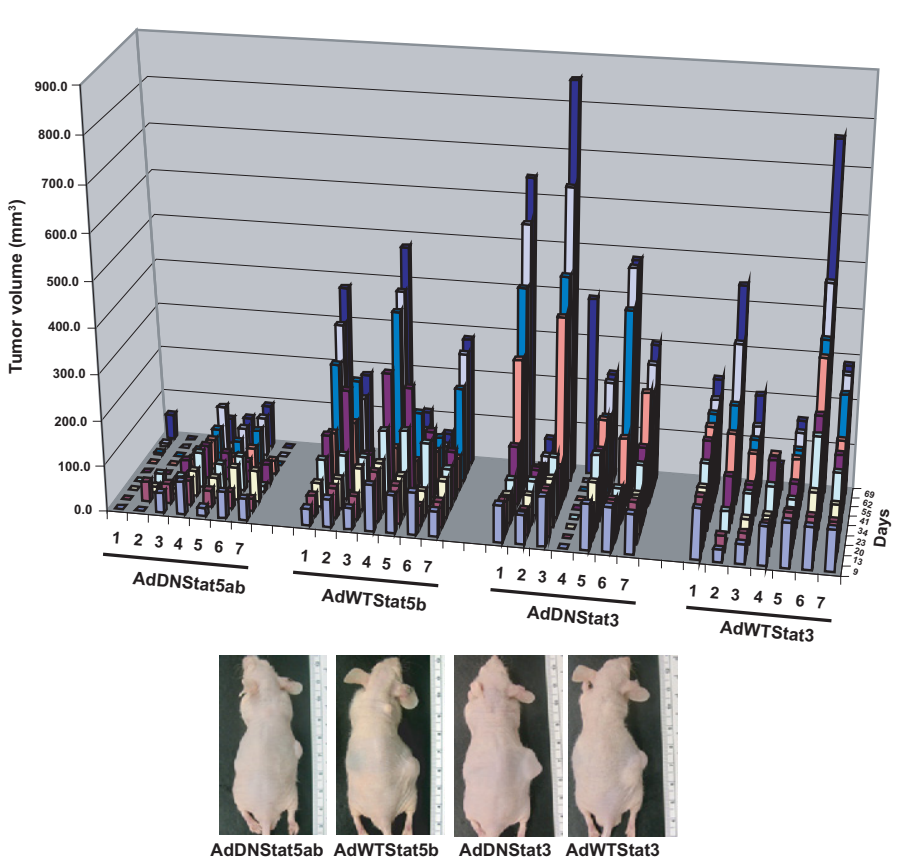

B

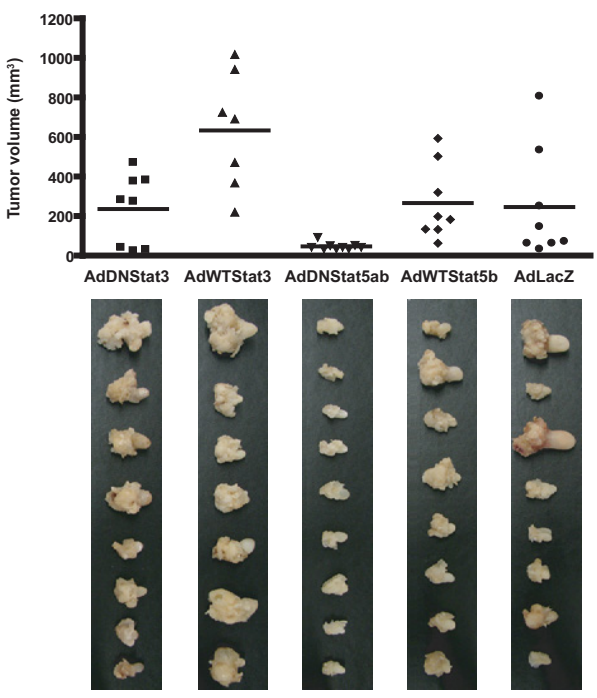

AdDNStat3 AdWTStat3 AdDNStat5ab AdWTStat5b AdLacZ
C

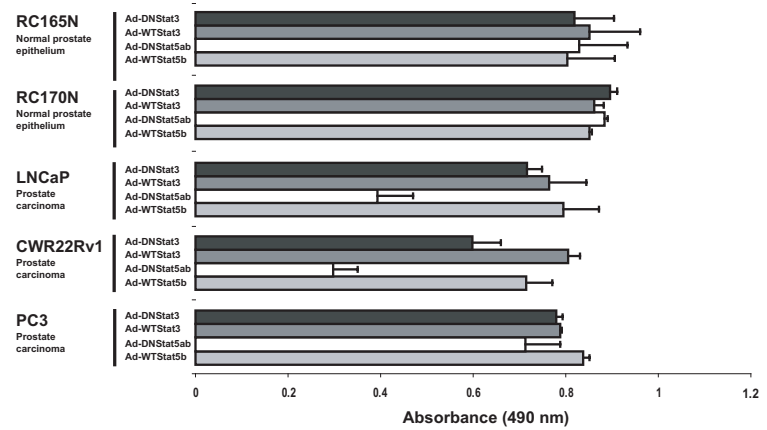

$E$

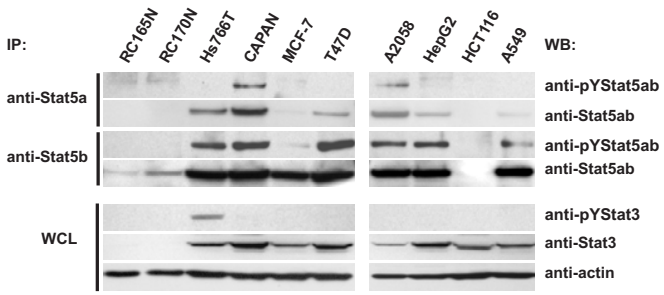

D

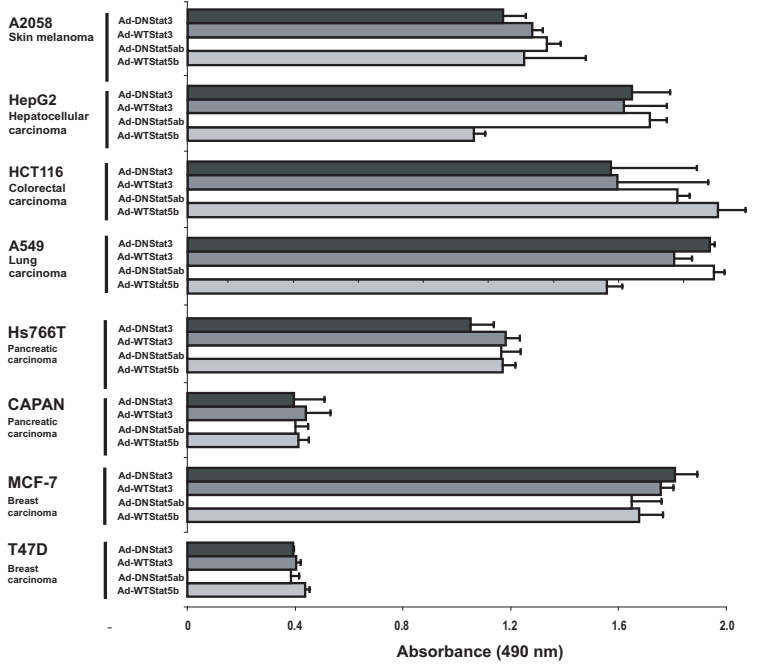

Figure 2. Inhibition of Stat $5 \mathrm{a} / \mathrm{b}$, not Stat3, has a major effect in blocking DU145 prostate cancer subcutaneous and orthotopic xenograft tumor growth in athymic nude mice. A: Subcutaneous tumor growth of DU145 prostate cancer cells infected with adenovirus (Ad) expressing DNStat5a/b, WTStat5b, DNStat3 or WTStat3. Twenty-four hours after the infection with AdDNStat $5 \mathrm{a} / \mathrm{b}$, AdWTStat $5 \mathrm{~b}$, AdDNStat3, or AdWTStat 3 at MOI 5 , the cells were inoculated subcutaneously into flanks of castrated athymic nude mice supplied with sustained-release $5 \alpha$-dihydrotestosterone (DHT)-pellets $\left(n=7\right.$ per group, 1 tumor per mouse, $20 \times 10^{6}$ DU145 cells per site, 1 DHT pellet/mouse). The tumor growth was measured once a week for 69 days. Tumor volumes were calculated using the formula $\mathrm{V}=(\pi / 6) \times d_{1} \times$ $\left(d_{2}\right)^{2}$, with $d_{1}$ and $d_{2}$ being two perpendicular tumor diameters. B: Orthotopic growth of DU145 prostate cancer cells infected with adenovirus (Ad) expressing DNStat3, WTStat3, DNStat5a/b, WTStat5b, or LacZ. DU145 cells were inoculated orthotopically in the dorsolateral prostates of athymic nude mice $\left(1 \times 10^{6}\right.$ DU145 cells per injection) supplied with DHT-pellets ( 1 pellet per mouse). Prior ( 24 hours) to the injection, the DU145 cells had been infected with AdDNStat $5 \mathrm{a} / \mathrm{b}$, AdWTStat5b, AdDNStat3, AdWTStat3, or AdLacZ at MOI 5. Mice were sacrificed 8 weeks after tumor cell inoculation, and the tumor volumes were calculated using the formula $\mathrm{V}=(\pi / 6) \times d_{1} \times\left(d_{2}\right)^{2}$, with $d_{1}$ and $d_{2}$ being two perpendicular tumor diameters. C: Inhibition of Stat5a/b does not affect the viability of normal human prostate epithelial cell lines, but caused a decrease in the number of viable LNCaP and CWR22Rv1 cells. Normal prostate epithelial cell lines, RC165N and RC170N, and human prostate cancer cell lines, LNCaP, CWR22Rv1, and PC-3, were infected with AdWTStat5b, AdDNStat5a/b, AdWTStat3, AdDNStat3, or AdLacZ at MOI 5. The cell viability was determined 72 hours after the adenoviral gene delivery by MTS (3-[4,5-dimethylthiazolyl-2]-2,5-diphenyl-tetrazolium bromide) metabolic activity assay. D: Melanoma (A5028), hepatocellular (HepG2), colorectal (HCT116), lung (A549), pancreatic (Hs766T and CAPAN), and breast (MCF-7 and T47D) cancer cell lines were infected with AdWTStat5b, AdDNStat5a/b, AdWTStat3, AdDNStat3, or AdLacZ at MOI 5, and the cell viability was determined 72 hours after the adenoviral gene delivery by MTS assay. The bars indicate mean \pm SD of triplicate determinations. E: Stat5a and Stat $5 b$ were immunoprecipitated using anti-Stat $5 \mathrm{a}$ and anti-Stat $5 \mathrm{~b}$ pAbs, respectively, and immunoprecipitates and whole cell lysates (WCL) were blotted with anti-Stat5a/b mAb or anti-Stat3 pAb, as indicated. Anti-actin immunoblotting of whole cell lysates indicates equal level of proteins in the immunoprecipitations. 
Table 1. Frequency of $S t a t 5 a / b$ and Stat 3 Activation in other Cancer Types than Prostate Cancer

\begin{tabular}{|c|c|c|c|c|c|}
\hline & Number of patients & $\%$ & & Number of patients & $\%$ \\
\hline Breast cancer & & & Breast cancer & & \\
\hline Stat5a/b activation status & 30 & 100 & Stat3 activation status & 34 & 100 \\
\hline Negative & 10 & 33 & Negative & 9 & 9 \\
\hline Positive & 20 & 67 & Positive & 31 & 91 \\
\hline Colon cancer & & & Colon cancer & & \\
\hline Stat5a/b activation status & 16 & 100 & Stat3 activation status & 19 & 100 \\
\hline Negative & 10 & 63 & Negative & 0 & 0 \\
\hline Positive & 6 & 37 & Positive & 19 & 100 \\
\hline Lung cancer (squamous) & & & Lung cancer (squamous) & & \\
\hline Stat5a/b activation status & 16 & 100 & Stat3 activation status & 18 & 100 \\
\hline Negative & 2 & 13 & Negative & 14 & 78 \\
\hline Positive & 14 & 87 & Positive & 4 & 22 \\
\hline Melanoma & & & Melanoma & & \\
\hline Stat5a/b activation status & 17 & 100 & Stat3 activation status & 20 & 100 \\
\hline Negative & 7 & 41 & Negative & 10 & 50 \\
\hline Positive & 10 & 59 & Positive & 10 & 50 \\
\hline
\end{tabular}

\section{Inhibition of Stat5a/b or Stat3 Does Not Affect} the Viability of Normal Human Prostate Epithelial Cells

We next tested the biological effects of Stat5a/b or Stat3 inhibition on the growth of other human prostate cancer cell lines LNCaP, CWR22Rv1, and PC-3. LNCaP and CWR22Rv1, which are both Stat5a/b and Stat3-positive, responded to Stat5a/b inhibition by significant reduction of viable cells (LNCaP; $P=0.0163$, CWR22Rv1; $P=0.0058$ ), but did not respond (LNCaP; $P=0.5532$ ) or responded only moderately to Stat3 inhibition (CWR22Rv1; $P=$ 0.0213). Inhibition of Stat5a/b or Stat3 did not affect the viability of PC-3 cells, which do not express Stat5a/b or Stat3 because of gene deletions, ${ }^{39}$ as expected (Figure $2 \mathrm{C}$ ).

To determine whether transcription factors Stat5a/b or Stat3 are critical for the viability of normal prostate epithelium, RC165N and RC170N normal human prostate epithelial cell lines $^{32}$ were infected with adenoviruses expressing DNStat5a/b, DNStat3, WTStat5b, or WTStat3 (Figure 2C). RC165N and RC170N have been established from benign prostate tissue, and both cell lines have been shown to express cytokeratin CK8, PSA, AR, and NKX3.1 characteristic to prostate luminal secretory cells. ${ }^{32}$ Importantly, neither of the nonmalignant prostate epithelial cell lines responded to inhibition of Stat5a/b or Stat3 by decreased cell viability (Figure 2C). However, the Stat3 protein expression in the nonmalignant prostate epithelial cell lines was below the detection level by Western blotting. Although Stat5b protein expression was detected in nonmalignant prostate epithelial cell lines and Stat5a expression was below the detection level with our antibodies, phospho-Stat5 immunoblotting indicated weak Stat5a phosphorylation in the RC165N and RC170N cells (Figure 2E).

Because transcription factor Stat $5 \mathrm{a} / \mathrm{b}$ may provide a therapeutic target protein for prostate cancer, we next aimed to establish how specific the effects of Stat5a/b inhibition are on the viability of prostate cancer cells compared with other cancers (Figure 2D). We first assessed the frequency of constitutive activation of Stat5a/b and Stat3 by immunohis- tochemistry in paraffin-embedded specimens of breast, colon, lung cancers, and melanomas (Table 1). Stat $5 \mathrm{a} / \mathrm{b}$ and Stat3 were in the active state in the majority of breast cancers (Stat5a/b 67\%; Stat3 91\%), and melanomas (Stat5a/b 59\%; Stat3 50\%), whereas 37\% colon cancers expressed activated Stat5a/b and $100 \%$ active Stat3. Furthermore, $87 \%$ of lung cancers expressed active Stat5a/b and $22 \%$ active Stat3 (Table 1). Stat5a/b or Stat3 inhibition by AdDNStat5a/b or AdDNStat3, respectively, did not suppress the viability of breast (MCF-7, T47D), melanoma (A2058), hepatocellular (HepG2), colorectal (HCT116), pancreas (Hs766T, CAPAN), or lung cancer (A549) cells (Figure 2D). Western blotting of immunoprecipitated Stat5a and Stat5b indicated Stat5a/b expression in all of the cell lines except HCT116 and PC-3 cells, ${ }^{2}$ whereas Stat3 was expressed in all cancer cell lines (Figure 2E). Taken together, these results suggest that Stat5b inhibition leads to cell death specifically in prostate cancer cell lines, but not in cell lines established from normal prostate epithelium. Moreover, the data suggest that although Stat5a/b may be constitutively active in cancers originating from other tissue types than prostate, its functional significance in those cancers is different from in prostate cancer.

\section{Stat3 Is the Key Inducer of Experimental Metastases Formation of Human Prostate Cancer Cells, whereas the Effects of Stat5a/b on Induction of Metastases Nodules Were Modest}

We recently showed that Stat3 induces a robust increase in lung metastases formation of human prostate cancer after tail-vein injections in athymic nude mice. ${ }^{31}$ Therefore, we next compared the effects of Stat $5 \mathrm{a} / \mathrm{b}$ to Stat 3 in promoting the in vivo metastasis formation of human prostate cancer cells. We performed an experimental metastases assay by infecting DU145 cells with adenoviruses expressing WTStat5a, WTStat5b, WTStat3, or LacZ at MOI 5. Twenty-four hours after the adenoviral gene delivery, we injected DU145 cells in athymic nude mice through the tail veins. The lungs were harvested after 8 


\section{A}

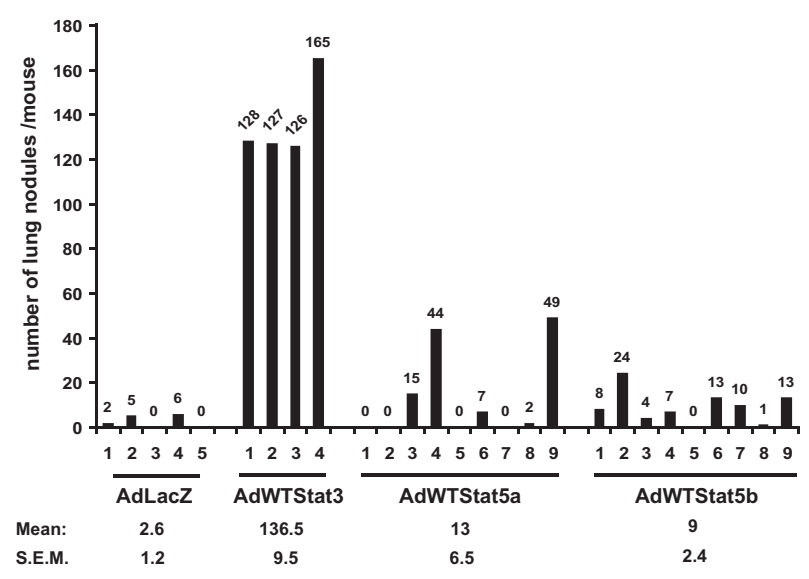

B

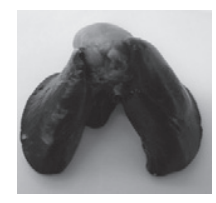

AdLacZ

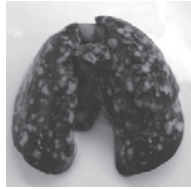

AdWTStat3

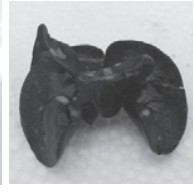

AdWTStat5a

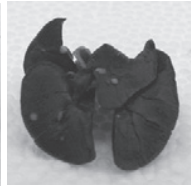

AdWTStat5b
Figure 3. Stat3 has a preferential role in promoting prostate cancer metastases formation in an experimental metastases assay. A: Athymic nude mice were injected with DU145 cells infected with adenovirus expressing LacZ, WTStat3, WTStat5a, or WTStat5b at MOI $5\left(1 \times 10^{6}\right.$ cells per mouse $)$ through the tail-vein. After 8 weeks, the lungs were harvested and stained with India Ink, bleached with Fekete's solution, and scored for surface lung metastases. B: Representative photographs of India Ink-stained lungs derived from athymic nude mice injected with LacZ, WTStat3, WTStat5a, or WTStat5b expressing DU145 cells after 8 weeks.

weeks and stained with India Ink, bleached with Fekete solution, and scored for surface lung metastases. As demonstrated in Figure 3A, the number of metastases in mice injected with DU145 cells infected with AdWTStat3 was increased by approximately 50 -fold when compared with mice injected with DU145 cell that had been infected with either AdLacZ. In contrast, WTStat5a increased the number of metastases by only fivefold and WTStat5b by fourfold in comparison with DU145 cells expressing LacZ. Quantitatively, injection of DU145 with AdWTStat3 cells resulted in an average of 137 (SEM = 9.5) metastases per lung, as compared with 2.6 per lung using DU145 cells infected with AdLacZ (SEM = 1.2) or AdWTStat5a (mean, 13, SEM = 6.5) or WTStat5b (mean, 9 , SEM = 2.4). Figure 3B demonstrates visually the white metastasis nodules in the lungs of nude mice. In conclusion, the data suggest that Stat3, not Stat5a/b, has a predominant role in promoting metastatic dissemination of human prostate cancer cells in an in vivo experimental metastases assay. This is the first side-by-side comparison of Stat5a/b to Stat3 in promotion of metastatic potential of human prostate cancer cells in vivo.

\section{Gene Expression Profiles Regulated by Stat5a/b Versus Stat3 in Human Prostate Cancer Cells}

To assess gene expression profiles of Stat5a/b and Stat3 in human prostate cancer cells, we inhibited Stat5 gene expression 48 hours before the gene expression analysis by Stat5a/b siRNA and Stat3 gene expression by Stat3 siRNA using scrambled siRNA as control (Ctrl) in two different human prostate cancer cell lines, DU145 and CWR22Rv1 (Figure 4A). Overall, 1409 genes in DU145 cells and 1344 genes in CWR22Rv1 cells were differentially expressed between Ctrl siRNA versus Stat5a/b and Stat3 siRNA groups using false discovery rate $<0.01$ on the full dataset of 15,992 genes (See Supplemental Tables S1 and S2 at http://ajp.amjpathol.org).

Importantly, only 15\% of the 1409 genes in DU145 cells were regulated by both Stat5a/b and Stat3, whereas $25 \%$ were regulated by Stat3 only and $60 \%$ were regulated by Stat5 only (Figure 4B). Similarly, only $11 \%$ of the 1344 genes in CWR22Rv1 cells were regulated by both transcription factors, whereas $30 \%$ were regulated by Stat3 only and $59 \%$ by Stat5a/b only (Figure $5 \mathrm{~A}$ ). To define functional groups within the Stat5a/b- and Stat3regulated genes, we used the descriptions from the Gene Ontology annotations as our tool. The Gene Ontology is constructed in a hierarchical manner with categories corresponding to each gene ontology identifier (GO ID) being potentially subdivided into more precise subcategories, each with its own GO ID. "The metastasis group" of genes was defined as a set of $88 \mathrm{GO}$ IDs and their subcategories (a total of 1975 GO IDs) corresponding to genes encoding proteins related to metastases processes. Correspondingly, "the apoptosis group" of genes was defined as a set of $21 \mathrm{GO}$ IDs and their subcategories (a total of 469 GO IDs) and "the proliferation group" as a set of $47 \mathrm{GO}$ IDs and their subcategories (a total of 943 GO IDs). Somewhat surprisingly, in each of our three comparisons (the genes regulated by Stat5 only, Stat3 only, or by both Stat5a/b and Stat3), the majority of the differentially expressed genes in both DU145 ( $n=1409)$ and CWR22Rv1 cells $(n=1344)$ between Ctrl siRNA and Stat5a/b or Stat3 siRNA groups were metastases-related. This was followed by genes related to proliferation, whereas the minority of the genes were apoptosis-related (Figures 4C and 5B).

The heatmaps demonstrate a hierarchical clustering of the expression values of the most differentially expressed genes (as determined by the smallest $P$ values) related to metastases, apoptosis or proliferation for the genes regulated by Stat5 only (Figure 4D; DU145, Figure 5C; CWR22Rv1), Stat3 only (Figure 4E; DU145, Figure 5D; CWR22Rv1), or the genes regulated by both Stat5a/b and Stat3 (Figure 4F; DU145, Figure 5E; CWR22Rv1). Red represents higher expression and green represents lower expression in the heatmaps, and the genes (rows) are re-ordered based on hierarchical clustering using the correlation metric. The heatmaps clearly illustrate the unique gene expression patterns of Stat5a/b versus Stat3 in both DU145 and CWR22Rv1 prostate cancer cell lines. Specifically, the majority of the genes that are up-regulated for example by Stat5a/b, and thus coded by red, are either down-regulated or not altered in the groups where Stat3 expression was selectively inhibited (Figures 4 and 5). In addition, the heatmaps (Figures 4 and 5) demonstrate the genes related to metastases, apoptosis, or proliferation, which are similarly regulated by both 
A

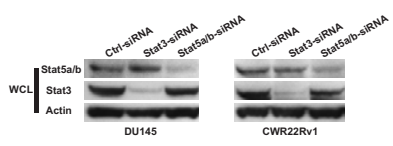

D

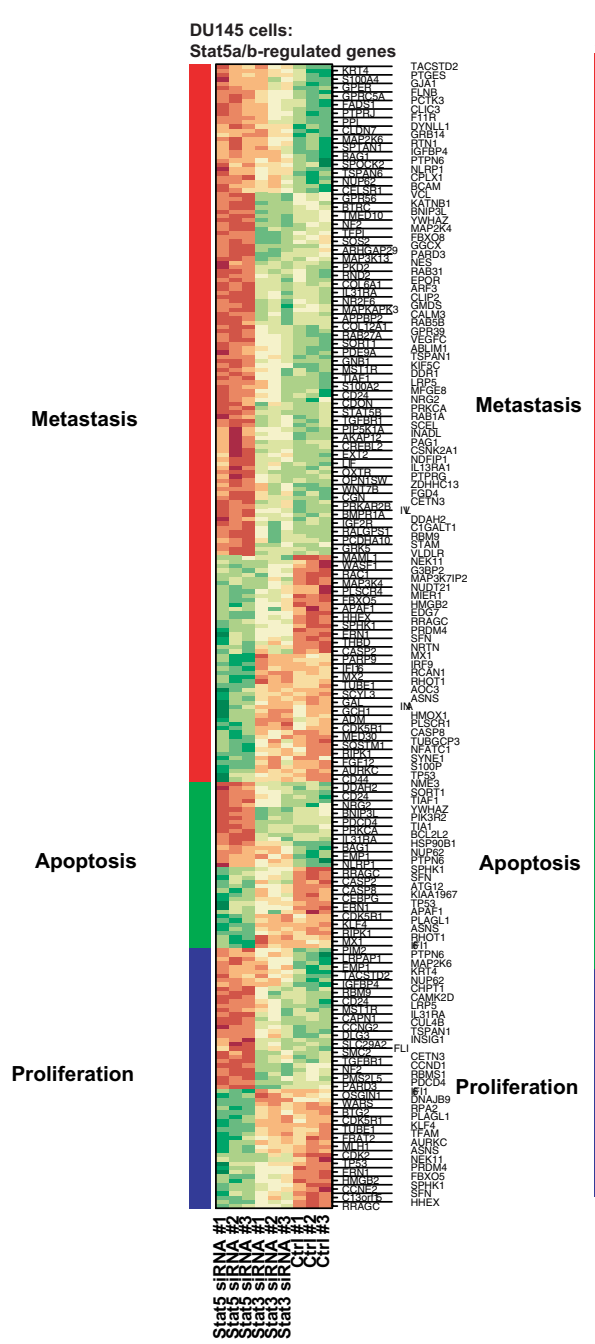

B

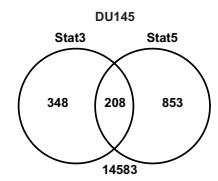

E

DU145 cells:

Stat3-regulated genes

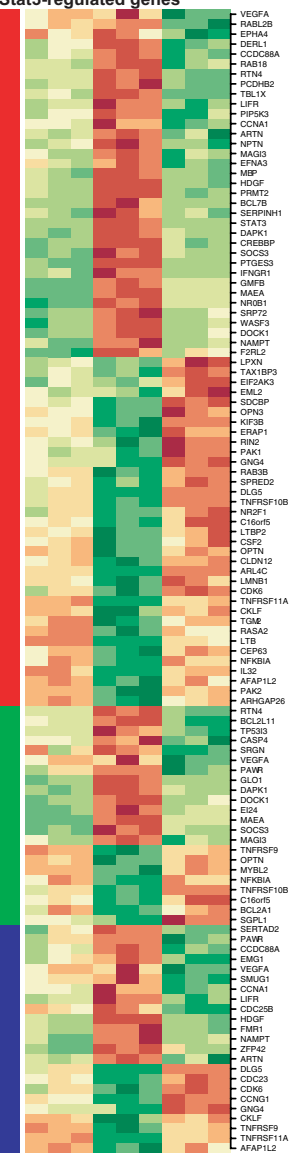

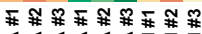

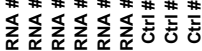

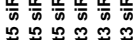

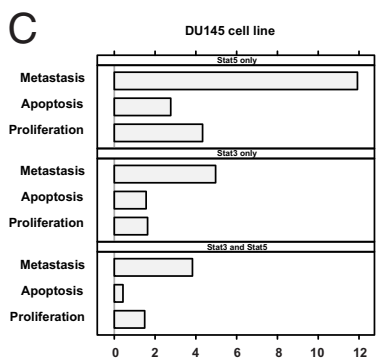

F

DU145 cells:

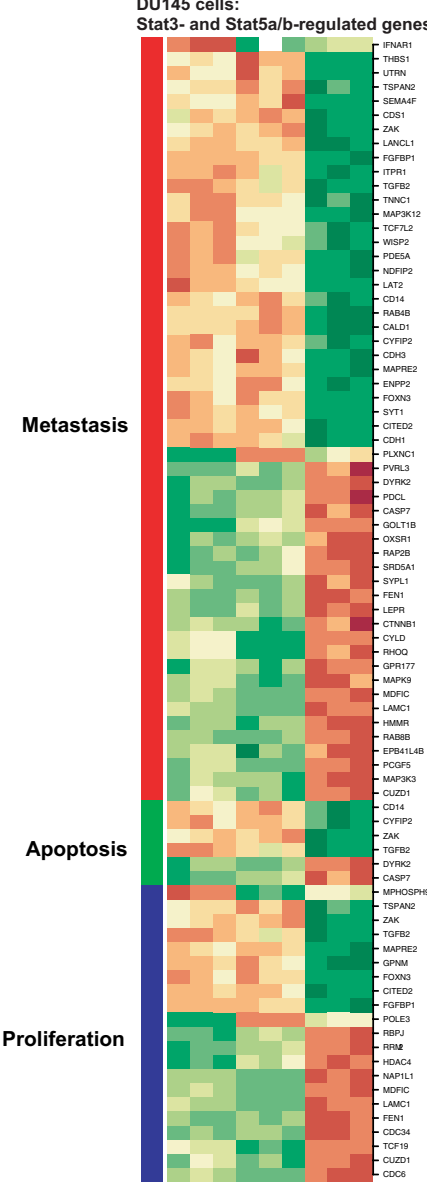

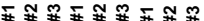

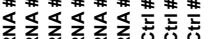

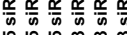

Figure 4. Identification of Stat 5 and/or Stat3-regulated genes in DU145 human prostate cancer cells. A: Inhibition of Stat5a/b or Stat3 protein expression human prostate cancer cells. DU145 and CWR22Rv1 cells were transfected with siRNA targeted to Stat5a/b or Stat3, with scrambled siRNA as control. Cells were harvested 48 hours after the transfection, lysed, and immunoblotted with anti-Stat $5 \mathrm{a} / \mathrm{b}$ mAb or anti-Stat $3 \mathrm{pAb}$, as indicated. The lower parts of the filters were blotted with anti-actin antibody to demonstrate equal loading (bottom panel). B: Venn-diagrams of Stat5a/b- and/or Stat3-regulated genes in DU145 human prostate cancer cells. C: The relative proportions of Stat $5 \mathrm{a} / \mathrm{b}$ versus Stat3 vs. Stat5-Stat3-regulated genes in DU145 prostate cancer cells related to metastases, proliferation, or apoptosis out of total of 1409 genes differentially expressed between control siRNA and Stat $5 \mathrm{a} / \mathrm{b}$ or Stat 3 siRNA using false-discovery rate $<0.01$ on the full dataset of 15,992 genes. The functional groups were identified using the Gene Ontology annotations. D: A heatmap showing the top differentially expressed genes by $\mathrm{Stat} 5 \mathrm{a} / \mathrm{b}$ (determined by the smallest $P$ values) related to metastases, apoptosis, or proliferation. Red represents higher expression, whereas green represent lower expression in the heatmap. For comparison, the levels of the gene expression for the corresponding genes in the groups where Stat3 was inhibited are shown in the middle of the heatmap. E: A heatmap showing the top differentially expressed genes by Stat 3 (determined by the smallest $P$ values) related to metastases, apoptosis, or proliferation. Red represents higher expression, whereas green represent lower expression in the heatmap. For comparison, the levels of the gene expression for the corresponding genes in the groups where Stat $5 \mathrm{a} / \mathrm{b}$ was inhibited are shown in the left side of the heatmap. F: A heatmap showing the top differentially expressed genes by Stat $5 \mathrm{a} / \mathrm{b}$ and Stat 3 (determined by the smallest $P$ values) related to metastases, apoptosis, or proliferation. Red represents higher expression, whereas green represent lower expression in the heatmap. 
A

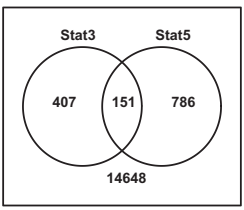

C

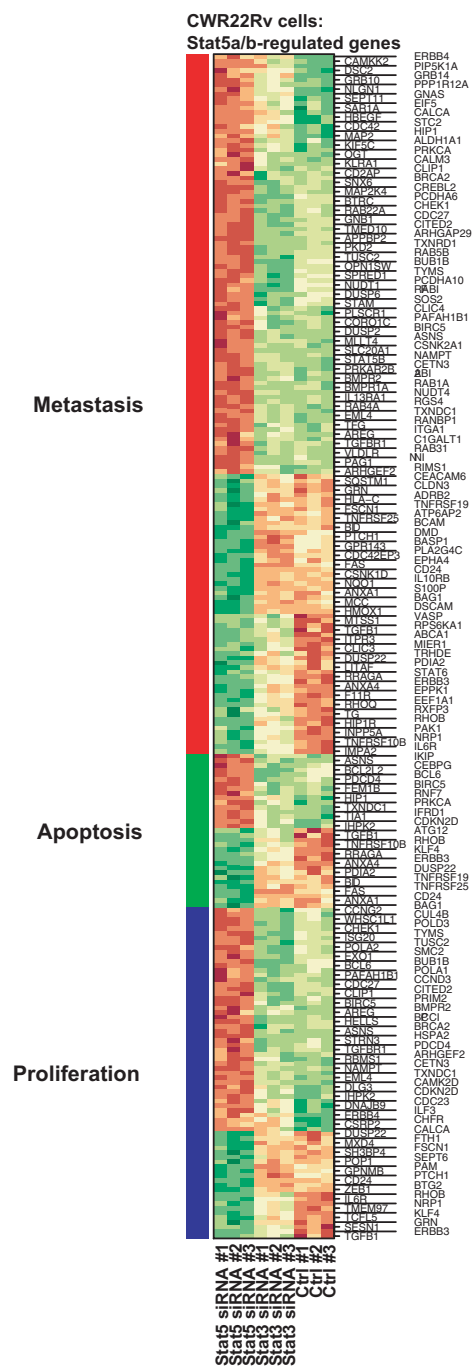

B

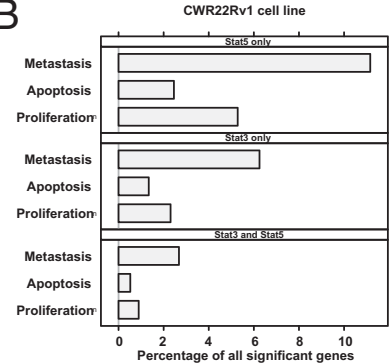

D

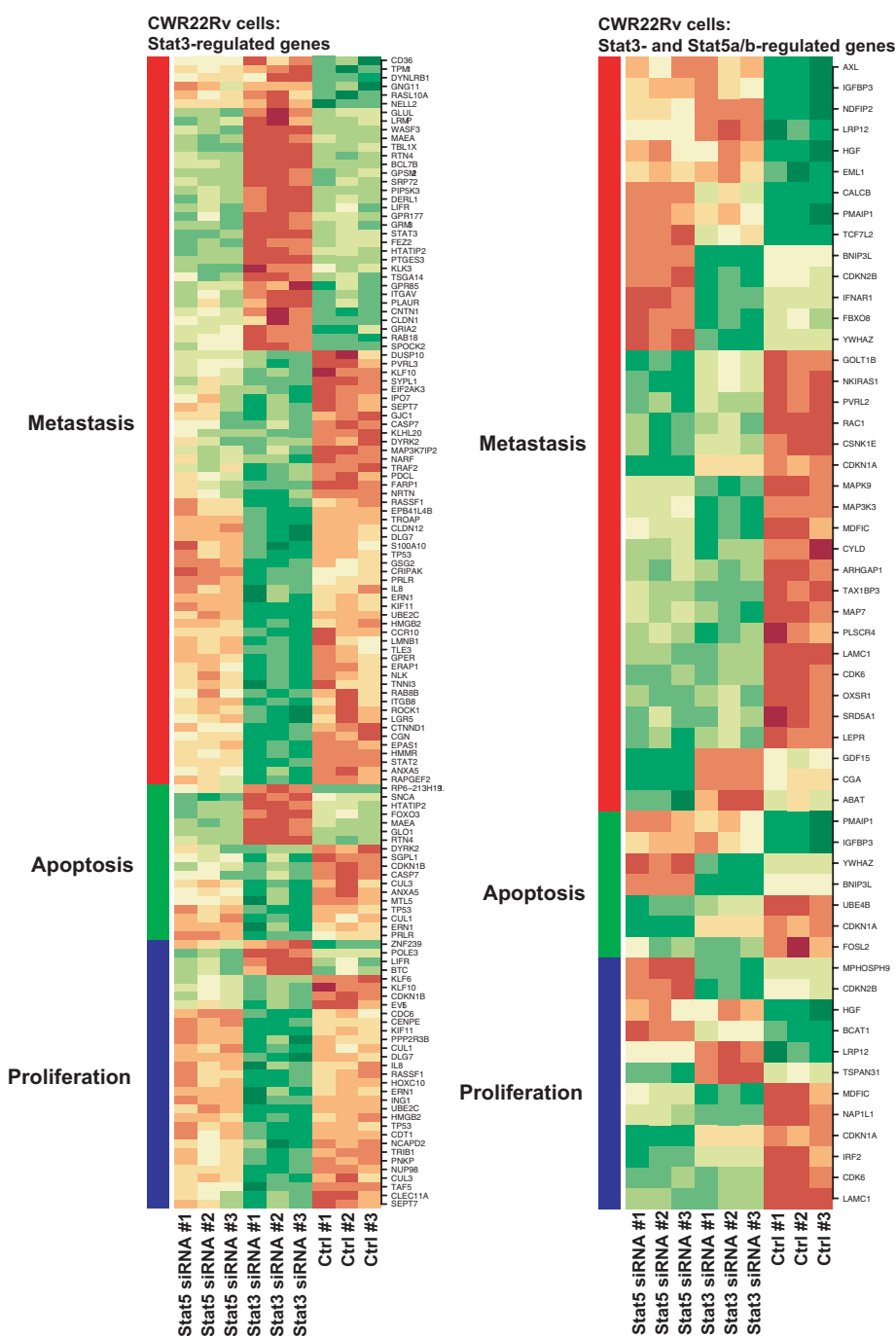

Figure 5. Identification of Stat 5 and/or Stat3-regulated genes in CWR22Rv1 human prostate cancer cells. A: Venn diagrams of Stat5a/b- and/or Stat3-regulated genes in CWR22Rv1 human prostate cancer cells. B: Transcriptional profiles of Stat5a/b versus Stat3-regulated genes in CWR22Rv1 prostate cancer cells related to metastases, proliferation, or apoptosis out of total of 1344 genes differentially expressed between control siRNA and Stat5a/b or Stat 3 siRNA using false-discovery rate $<0.01$ on the full dataset of 15,992 genes. The functional groups were identified using the Gene Ontology annotations. C: A heatmap showing the top differentially expressed genes by Stat $5 \mathrm{a} / \mathrm{b}$ (determined by the smallest $P$ values) in CWR22Rv1 cells related to metastases, apoptosis, or proliferation. Red represents higher expression, whereas green represent lower expression in the heatmap. For comparison, the levels of the gene expression for the corresponding genes in the groups where Stat 3 was inhibited are shown in the middle of the heatmap. D: A heatmap showing the top differentially expressed genes by Stat3 (determined by the smallest $P$ values) in CWR22Rv1 cells related to metastases, apoptosis, or proliferation. Red represents higher expression, whereas green represent lower expression in the heatmap. For comparison, the levels of the gene expression for the corresponding genes in the groups where Stat $5 \mathrm{a} / \mathrm{b}$ was inhibited are shown on the left side of the heatmap. E: A heatmap showing the top differentially expressed genes by Stat $5 \mathrm{a} / \mathrm{b}$ and Stat 3 (determined by the smallest $P$ values) in CWR22Rv1 cells related to metastases, apoptosis, or proliferation. Red represents higher expression, whereas green represent lower expression in the heatmap.

Stat5a/b and Stat3 (See Supplemental Tables S1 and S2 at $h$ ttp://ajp.amjpathol.org). In both cell lines, inhibition of Stat5a/b led to down-regulation of PDCD4, a protein that mediates the inhibition of neoplastic transformation. ${ }^{40}$ In addition, inhibition of Stat5a/b induced in both cell lines the expression of Kruppel-like factor 4, which is a known repressor of CyclinD1 and mediates growth suppression. ${ }^{41,42}$ VEGF-C and collagen types VI and XII were 
Table 2. Primers for Quantitative PCR Analysis

\begin{tabular}{|c|c|c|}
\hline Gene & Direction & Sequence \\
\hline IL6R & $\begin{array}{l}\text { Forward } \\
\text { Reverse }\end{array}$ & $\begin{array}{l}\text { 5'-GGGCTCTGAAGGAAGGCAAGACA-3' } \\
5^{\prime} \text {-CGGTGGGGAGATGAGAGGAACA-3' }\end{array}$ \\
\hline$P D C D 4$ & $\begin{array}{l}\text { Forward } \\
\text { Reverse }\end{array}$ & $\begin{array}{l}5^{\prime}-\text { TATGATGTGGAGGAGGTGGATGTGA-3' } \\
5^{\prime}-\text {-CCTTTCATCCAAAGGCAAAACTACAC-3' }\end{array}$ \\
\hline$K L F-4$ & $\begin{array}{l}\text { Forward } \\
\text { Reverse }\end{array}$ & $\begin{array}{l}5^{\prime}-\text { AGAGGAGCCCAAGCCAAAGAGG-3' } \\
5^{\prime}-\text { CCACAGCCGTCCCAGTCACAGT-3 }\end{array}$ \\
\hline MAEA & $\begin{array}{l}\text { Forward } \\
\text { Reverse }\end{array}$ & $\begin{array}{l}5^{\prime} \text {-GAAGCTCAGCGTCCTCAAGA-3' } \\
5^{\prime} \text {-CTGCTATGCTCTTTGAGGTGC-3' }\end{array}$ \\
\hline YWHAZ & $\begin{array}{l}\text { Forward } \\
\text { Reverse }\end{array}$ & $\begin{array}{l}5^{\prime}-\text { CGTTACTTGGCTGAGGTTGC-3' } \\
5^{\prime} \text {-CAGAGAAGTTAAGGGCCAGAC-3' }\end{array}$ \\
\hline VEGF-A & $\begin{array}{l}\text { Forward } \\
\text { Reverse }\end{array}$ & $\begin{array}{l}\text { 5'-CACTGAGGAGTCCAACATCAC-3' } \\
5^{\prime}-\text { TTCTTGTCTTGCTCTATCTTTCTTTG-3' }\end{array}$ \\
\hline Plexin C1 & $\begin{array}{l}\text { Forward } \\
\text { Reverse }\end{array}$ & $\begin{array}{l}5^{\prime}-\text {-GCACCGTGGTAATGAACAGG- } 3^{\prime} \\
5^{\prime}-\text { GAACGAGTTTGTAGAAAACAGG-3' }\end{array}$ \\
\hline
\end{tabular}

identified among the metastases-related genes regulated by Stat5a/b in DU145 cells, whereas inhibition of Stat3 led to down-regulation of Reticulon 4, BCL7B, and Macrophage Erythroblast Attacher ${ }^{43}$ in both prostate cancer cell lines. We verified by quantitative PCR of a set of six genes that the changes in mRNA levels corresponded with the Affymetrix data (Table 2; see also Supplemental Figure S1 at http://ajp.amjpathol.org). In summary, the data presented here demonstrate that the gene expression profiles of transcription factors Stat5a/b and Stat3 differ in human prostate cancer cells.

\section{Discussion}

Protein kinase signaling pathways, such as Jak2-Stat5a/b or Jak2-Stat3, are of significant interest in the search for new molecular targets for therapy development for prostate cancer. In this work, we compared side-by-side the biological effects of two transcription factors of the Stat family, Stat5a/b and Stat3, in prostate cancer. We demonstrate that Stat5b has a key role over Stat3 in promoting the viability of prostate cancer cells in culture and growth of subcutaneous and orthotopic prostate tumors in nude mice. Stat3, in turn, is the predominant promoter of metastases formation in an experimental metastases assay in vivo. Of the two Stat5 homologs, Stat5b was more important for prostate cancer cell viability than Stat5a. Intriguingly, Stat5a/b regulates largely a different set of genes than Stat3 in prostate cancer cells, which provides the molecular basis for the different biological effects mediated by these two closely related Stat transcription factors in prostate cancer cells.

This is the first side-by-side comparison of the biological effects of Stat5a/b versus Stat3 in human prostate cancer cells in vitro and in vivo. This is important because it is well established that Stat5a/b and Stat3 are both constitutively active in advanced clinical prostate cancers. $^{3-6,23}$ The relative importance of Stat5a/b versus Stat3 in promoting prostate cancer cell viability and tumor growth has been unclear. Here, our results demonstrate that inhibition of Stat5a/b induced extensive death of prostate cancer cells in culture in three different human prostate cancer cell lines (DU145, CWR22Rv1, and LNCaP), whereas the effects of Stat3 inhibition on prostate cancer cell viability were modest. Specifically, inhibition of Stat3 had no effect on the number of LNCaP cells, and the effect of Stat3 inhibition on the number of DU145 or CWR22Rv1 cells was clearly less pronounced than that of Stat5 inhibition in the side-by-side comparison. PC-3 cells, which lack Stat5a/b and Stat3 because of gene deletions, ${ }^{39}$ did not respond to $S t a t 5 a / b$ or Stat3 inhibition. The data presented here were not dependent on the methodology used because similar results were obtained by two different methodological approaches, adenoviral gene delivery of DN mutants of Stat5a/b or Stat3, and Stat5a/b versus Stat3 siRNA inhibition. Moreover, we verified by Western blotting that the siRNAs targeting Stat5a/b or Stat3 did not have cross-reactivity between the three transcription factors. In addition to the effects in cell culture conditions, inhibition of $S t a t 5 a / b$ reduced both subcutaneous and orthotopic prostate tumor growth in nude mice, whereas the effects of Stat3 inhibition were less pronounced. The results of this study also point out that of the two Stat5 homologs, Stat5b may be more important for prostate cancer cell viability and survival than Stat5a. Future work will need to confirm this observation in tumor growth studies in vivo.

The second key finding of this work was the demonstration of a predominant role of Stat3, not Stat5a/b, in promoting metastatic dissemination of human prostate cancer cells in an in vivo experimental metastases assay. We recently demonstrated that Stat3, through Jak2 activation, induced a migratory phenotype of DU145 and PC-3 cells through regulation of the actin cytoskeleton and the microtubule network. ${ }^{31}$ Moreover, Stat3 promoted metastases formation of human prostate cancer cells in vivo. This finding led us to compare Stat3 versus Stat5 in induction of metastatic behavior of human prostate cancer cells. Here we showed that Stat3 induced a 50 -fold increase in the number of metastases in the lungs of nude mice after tail-vein injection of DU145 prostate cancer cells, whereas Stat5a/b increased the number of metastases by four- to fivefold. It is important to note that the Stat3 induction of lung metastases formation is unlikely to be attributable to Stat3 promotion of survival of human prostate cancer cells in circulation and in the lung microenvironment, because the effects of Stat3 inhibition on prostate cancer cell viability were only minor. These 
observations support the concept that Stat 3 induces metastatic behavior of prostate cancer cells by distinct molecular mechanisms that need to be defined in detail.

To understand the molecular background of the differential biological effects of Stat5a/b versus Stat3 in prostate cancer, we examined the gene expression profiles of Stat5a/b versus Stat3 in two different human prostate cancer cell lines. The most important knowledge gained from these studies is that Stat5a/b and Stat3 for the most part regulate different sets of genes in human prostate cancer cells. Both Stat5a/b and Stat3 recognize the GAS consensus sequence ${ }^{21}$ and, therefore, the differential gene expression patterns regulated by Stat5a/b versus Stat3 are likely a result of a number of different factors. These include different expression levels of co-activators, co-repressors, as well as negative regulators of Stat signaling such as phosphatases, PIAS proteins, and cytokineinducible suppressors of cytokine signaling proteins. Moreover, the spacing between palindromic half-sites within the promoter is important in Stat5a/b versus Stat3 selection by GAS elements. In addition to the sequence, the extent of palindromic sites and also the nucleotides in between and outside the palindrome half-sites can contribute to the strength and selectivity of Stat5/3 binding to GAS elements. ${ }^{21}$ Somewhat surprisingly, the majority of the genes regulated by Stat5a/b as well as Stat3 were metastases-related. This may, however, be affected by the selection of the GO IDs for each functional group of the gene expression analysis.

Finally, Stat5a/b and Stat3 are in the active state in a significant fraction of human melanomas, breast, lung, and colon cancers. At the same time, inhibition of Stat5a/b or Stat3 did not affect the viability of cell lines established from melanomas, liver, colon, pancreas, or lung cancers, suggesting that the biological roles of Stat5a/b and Stat3 in these cancer types are different from in prostate cancer. It is known, however, that presence of active Stat5a/b in breast cancer predicts favorable clinical outcome, ${ }^{44}$ whereas active Stat5a/b expression in prostate cancer predicts early disease recurrence. ${ }^{3}$ The differential biological effects mediated by Stat5 in various tissues are likely to be attributable to several factors such as epigenetic regulation of chromatin structure and the availability of Stat5responsive genes for transcription, expression of coactivators and co-repressors in a given tissue, as well as expression levels of negative regulators of Stat5 action.

In conclusion, this work provides the first functional and gene expression profile comparison of transcription factors Stat5a/b and Stat3 in prostate cancer. The results indicate different roles for Stat5a/b and Stat3 in the progression of prostate cancer: Stat5a/b promotes viability and survival of the cells, whereas Stat3 stimulates metastatic behavior of cancer cells. Ongoing work aims to determine whether Jak2 is the common denominator for activation of both Stat5a/b and Stat3 in clinical prostate cancers using organ cultures of clinical prostate cancers as the experimental model system. This is important because the newly developed Jak2 inhibitors ${ }^{45}$ may provide the therapeutic means to target both transcription factors and inhibit two different aspects of prostate cancer progression at the same time.

\section{Acknowledgments}

We thank Dr. Hallgeir Rui (Kimmel Cancer Center [KCC], Thomas Jefferson University, Philadelphia, PA) for AdWTStat3, AdDNStat3, AdWTJak2, and AdDNJak2 constructs. We also thank Dr. Erik Knudsen (KCC) for the cell lines A2058, HepG2, HCT116, and A549 used in this study, Dr. Johng Rhimm (Center for Prostate Disease Research, CPDR) for RC165N and RC170N, and Dr. Jonathan Brody (KCC) for the pancreatic cell lines Hs766T and CAPAN.

\section{References}

1. Damber JE, Aus G: Prostate cancer. Lancet 2008, 371:1710-1721

2. Ahonen TJ, Xie J, LeBaron MJ, Zhu J, Nurmi M, Alanen K, Rui H, Nevalainen MT: Inhibition of transcription factor Stat5 induces cell death of human prostate cancer cells. J Biol Chem 2003, 278: 27287-27292

3. Li H, Zhang Y, Glass A, Zellweger T, Gehan E, Bubendorf L, Gelmann EP, Nevalainen MT: Activation of signal transducer and activator of transcription-5 in prostate cancer predicts early recurrence. Clin Cancer Res 2005, 11:5863-5868

4. Li H, Ahonen TJ, Alanen K, Xie J, LeBaron MJ, Pretlow TG, Ealley EL, Zhang Y, Nurmi M, Singh B, Martikainen PM, Nevalainen MT: Activation of signal transducer and activator of transcription 5 in human prostate cancer is associated with high histological grade. Cancer Res 2004, 64:4774-4782

5. Mora LB, Buettner R, Seigne J, Diaz J, Ahmad N, Garcia R, Bowman T, Falcone R, Fairclough R, Cantor A, Muro-Cacho C, Livingston S, Karras J, Pow-Sang J, Jove R: Constitutive activation of Stat3 in human prostate tumors and cell lines: direct inhibition of Stat3 signaling induces apoptosis of prostate cancer cells. Cancer Res 2002, 62:6659-6666

6. Campbell CL, Jiang Z, Savarese DM, Savarese TM: Increased expression of the interleukin-11 receptor and evidence of STAT3 activation in prostate carcinoma. Am J Pathol 2001, 158:25-32

7. Dhir R, Ni Z, Lou W, DeMiguel F, Grandis JR, Gao AC: Stat3 activation in prostatic carcinomas. Prostate 2002, 51:241-246

8. Horinaga M, Okita H, Nakashima J, Kanao K, Sakamoto M, Murai M Clinical and pathologic significance of activation of signal transducer and activator of transcription 3 in prostate cancer. Urology 2005, 66:671-675

9. Dagvadorj A, Collins S, Jomain JB, Abdulghani J, Karras J, Zellweger T, Li H, Nurmi M, Alanen K, Mirtti T, Visakorpi T, Bubendorf L, Goffin V, Nevalainen MT: Autocrine prolactin promotes prostate cancer cell growth via Janus kinase-2-signal transducer and activator of transcription-5a/b signaling pathway. Endocrinology 2007, 148:3089-3101

10. Dagvadorj A, Kirken RA, Leiby B, Karras J, Nevalainen MT: Transcription factor signal transducer and activator of transcription 5 promotes growth of human prostate cancer cells in vivo. Clin Cancer Res 2008, 14:1317-1324

11. Barton BE, Karras JG, Murphy TF, Barton A, Huang HF: Signal transducer and activator of transcription 3 (STAT3) activation in prostate cancer: direct STAT3 inhibition induces apoptosis in prostate cancer lines. Mol Cancer Ther 2004, 3:11-20

12. Lee SO, Lou W, Hou M, de Miguel F, Gerber L, Gao AC: Interleukin-6 promotes androgen-independent growth in LNCaP human prostate cancer cells. Clin Cancer Res 2003, 9:370-376

13. Inle JN: The Stat family in cytokine signaling. Curr Opin Cell Biol 2001, 13:211-217

14. Levy DE, Darnell JE Jr: Stats: transcriptional control and biological impact. Nat Rev Mol Cell Biol 2002, 3:651-662

15. Darnell JE Jr: STATs and gene regulation. Science 1997, 277 1630-1635

16. Kirken RA, Malabarba MG, Xu J, Liu X, Farrar WL, Hennighausen L, Larner AC, Grimley PM, Rui H: Prolactin stimulates serine/tyrosine phosphorylation and formation of heterocomplexes of multiple Stat5 isoforms in Nb2 lymphocytes. J Biol Chem 1997, 272:14098-14103

17. Kirken RA, Malabarba MG, Xu J, DaSilva L, Erwin RA, Liu X, Hennighausen L, Rui H, Farrar WL: Two discrete regions of interleukin-2 (IL2) receptor beta independently mediate IL2 activation of a 
PD98059/rapamycin/wortmannin-insensitive Stat5a/b serine kinase. J Biol Chem 1997, 272:15459-15465

18. Yamashita H, Nevalainen MT, Xu J, LeBaron MJ, Wagner KU, Erwin RA, Harmon JM, Hennighausen L, Kirken RA, Rui H: Role of serine phosphorylation of Stat5a in prolactin-stimulated beta- casein gene expression. Mol Cell Endocrinol 2001, 183:151-163

19. Becker S, Groner B, Muller CW: Three-dimensional structure of the Stat3beta homodimer bound to DNA. Nature 1998, 394:145-151

20. Chen X, Vinkemeier U, Zhao Y, Jeruzalmi D, Darnell JE, Jr., Kuriyan J: Crystal structure of a tyrosine phosphorylated STAT-1 dimer bound to DNA. Cell 1998, 93:827-839

21. Decker T, Kovarik P, Meinke A: GAS elements: a few nucleotides with a major impact on cytokine-induced gene expression. J Interferon Cytokine Res 1997, 17:121-134

22. Kazansky AV, Spencer DM, Greenberg NM: Activation of signal transducer and activator of transcription 5 is required for progression of autochthonous prostate cancer: evidence from the transgenic adenocarcinoma of the mouse prostate system. Cancer Res 2003, 63:8757-8762

23. Tan SH, Dagvadorj A, Shen F, Gu L, Liao Z, Abdulghani J, Zhang Y, Gelmann EP, Zellweger T, Culig Z, Visakorpi T, Bubendorf L, Kirken RA, Karras J, Nevalainen MT: Transcription factor Stat5 synergizes with androgen receptor in prostate cancer cells. Cancer Res 2008, 68:236-248

24. Huang HF, Murphy TF, Shu P, Barton AB, Barton BE: Stable expression of constitutively-activated STAT3 in benign prostatic epithelial cells changes their phenotype to that resembling malignant cells. Mol Cancer 2005, 4:2

25. Chen T, Wang LH, Farrar WL: Interleukin 6 activates androgen receptor-mediated gene expression through a signal transducer and activator of transcription 3-dependent pathway in LNCaP prostate cancer cells. Cancer Res 2000, 60:2132-2135

26. Matsuda T, Junicho A, Yamamoto T, Kishi H, Korkmaz K, Saatcioglu F, Fuse $\mathrm{H}$, Muraguchi A: Cross-talk between signal transducer and activator of transcription 3 and androgen receptor signaling in prostate carcinoma cells. Biochem Biophys Res Commun 2001, 283:179-187

27. Ueda T, Bruchovsky N, Sadar MD: Activation of the androgen receptor N-terminal domain by interleukin-6 via MAPK and STAT3 signal transduction pathways. J Biol Chem 2002, 277:7076-7085

28. Yang L, Wang L, Lin HK, Kan PY, Xie S, Tsai MY, Wang PH, Chen YT, Chang C: Interleukin-6 differentially regulates androgen receptor transactivation via PI3K-Akt. STAT3, and MAPK, three distinct signal pathways in prostate cancer cells Biochem Biophys Res Commun 2003, 305:462-469

29. DeMiguel F, Lee SO, Lou W, Xiao X, Pflug BR, Nelson JB, Gao AC: Stat3 enhances the growth of LNCaP human prostate cancer cells in intact and castrated male nude mice. Prostate 2002, 52:123-129

30. Lou W, Ni Z, Dyer K, Tweardy DJ, Gao AC: Interleukin-6 induces prostate cancer cell growth accompanied by activation of stat3 signaling pathway. Prostate 2000, 42:239-242

31. Abdulghani J, Gu L, Dagvadorj A, Lutz J, Leiby B, Bonuccelli G, Lisanti MP, Zellweger T, Alanen K, Mirtti T, Visakorpi T, Bubendorf L,
Nevalainen MT: Stat3 promotes metastatic progression of prostate cancer. Am J Pathol 2008, 172:1717-1728

32. Gu Y, Li H, Miki J, Kim KH, Furusato B, Sesterhenn IA, Chu WS, McLeod DG, Srivastava S, Ewing CM, Isaacs WB, Rhim JS: Phenotypic characterization of telomerase-immortalized primary non-malignant and malignant tumor-derived human prostate epithelial cell lines. Exp Cell Res 2006, 312:831-843

33. Sultan AS, Xie J, LeBaron MJ, Ealley EL, Nevalainen MT, Rui H: Stat5 promotes homotypic adhesion and inhibits invasive characteristics of human breast cancer cells. Oncogene 2005, 24:746-760

34. Irizarry RA, Hobbs B, Collin F, Beazer-Barclay YD, Antonellis KJ, Scherf U, Speed TP: Exploration, normalization, and summaries of high density oligonucleotide array probe level data. Biostatistics 2003, 4:249-264

35. Falcon S, Gentleman R: Using GOstats to test gene lists for GO term association. Bioinformatics 2007, 23:257-258

36. Gentleman RC, Carey VJ, Bates DM, Bolstad B, Dettling M, Dudoit S, Ellis B, Gautier L, Ge Y, Gentry J, Hornik K, Hothorn T, Huber W, lacus S, Irizarry R, Leisch F, Li C, Maechler M, Rossini AJ, Sawitzki G, Smith C, Smyth G, Tierney L, Yang JY, Zhang J: Bioconductor: open software development for computational biology and bioinformatics. Genome Biol 2004, 5:R80

37. Smyth GK: Linear models and empirical bayes methods for assessing differential expression in microarray experiments. Stat Appl Genet Mol Biol 2004, 3:Article3

38. Benjamini Y, Hochberg, Y: Controlling the false discovery rate: A practical and powerful approach to multiple testing. 1995, pp 289-300

39. Clark J, Edwards S, Feber A, Flohr P, John M, Giddings I, Crossland S Stratton MR, Wooster R, Campbell C, Cooper CS: Genome-wide screening for complete genetic loss in prostate cancer by comparative hybridization onto cDNA microarrays. Oncogene 2003, 22:1247-1252

40. Yang HS, Jansen AP, Nair R, Shibahara K, Verma AK, Cmarik JL, Colburn NH: A novel transformation suppressor. Pdcd4, inhibits AP-1 transactivation but not NF-kappaB or ODC transactivation Oncogene 2001, 20:669-676

41. Chen X, Johns DC, Geiman DE, Marban E, Dang DT, Hamlin G, Sun R, Yang VW: Kruppel-like factor 4 (gut-enriched Kruppel-like factor) inhibits cell proliferation by blocking $\mathrm{G} 1 / \mathrm{S}$ progression of the cell cycle. J Biol Chem 2001, 276:30423-30428

42. Shie JL, Chen ZY, Fu M, Pestell RG, Tseng CC: Gut-enriched Kruppel-like factor represses cyclin D1 promoter activity through Sp1 motif. Nucleic Acids Res 2000, 28:2969-2976

43. Hanspal M, Hanspal JS: The association of erythroblasts with macrophages promotes erythroid proliferation and maturation: a 30-kD heparin-binding protein is involved in this contact. Blood 1994, 84:3494-3504

44. Nevalainen MT, Xie J, Torhorst J, Bubendorf L, Haas P, Kononen J, Sauter G, Rui H: Signal transducer and activator of transcription-5 activation and breast cancer prognosis. J Clin Oncol 2004, 22:2053-2060

45. Gozgit JM, Bebernitz G, Patil P, Ye M, Parmentier J, Wu J, Su N, Wang T, loannidis S, Davies A, Huszar D, Zinda M: Effects of the JAK2 inhibitor. AZ960, on Pim/BAD/BCL-xL survival signaling in the human JAK2 V617F cell line SET-2. J Biol Chem 2008, 283:32334-32343 